the lowest and highest tension. In a good section of the cochlea the spiral ligament will be seen to exhibit a progressive differentiation in bulk and closeness of texture not inconsistent with such extremes of tension. Further, the upper and lower limit of tension can be roughly calculated, and the resulting values are possible ones. The highest is only about a quarter of the breaking strain of tendinous structures of the same fineness.

Helmholtz recognised quite clearly the bearing of the "load " on the basilar fibres in rendering possible the small scale of the cochlea, though he failed to realise the progressive differentiation of the fibres for mass thereby effected. He says, "That such short strings should be capable of corresponding with such deep tones must be explained by their being loaded in the basilar membrane with all kind of solid formations; the fluid of both galleries in the cochlea must also be considered as weighting the membrane, because it cannot move without a kind of wave motion in that fluid" (second English edition translated by A. J. Ellis, p. I46).

No doubt if Helmholtz had known the anatomical structure of the spiral ligament, which was described by Albert Gray in I900, the whole mechanism of the cochlea would have been clear to him.

387 Glossop Road, Sheffield. GEORGE WILKINSON.

\section{Stirling's Theorem.}

IN starting from $d n=\mathrm{I}$ and then making $d n$ infinitesimal, Dr. Satterly's demonstration in NATURE of February $\mathrm{I}_{7}$, p. 220 , is scarcely convincing, and the error introduced by this step is represented in his answer by the absence of the factor $\mathrm{I} / \sqrt{n}$ or the term $\frac{1}{2} \log n$, neither of which is entirely negligible when $n$ is large. I suggest the following adaptation of his proof, which avoids, I think, the inconsistency referred to above.

$$
\log |\underline{n+1}-\log | n=\log (n+\mathrm{r}) .
$$

\section{$\therefore$ by Taylor's theorem}

$$
\left(\mathrm{D}+\mathrm{D}^{2} / \underline{2}+\ldots\right) \log \mid \underline{n}=\log n+\mathrm{I} / n+\ldots
$$

all terms on the right being negligible after the first when $n$ is large.

$$
\begin{aligned}
\therefore \log \underline{\mid n} & =\frac{\mathrm{I}}{\mathrm{D}+\mathrm{D}^{2} / \mid \underline{2}+\ldots} \log n \\
& =\frac{\mathrm{I}}{\mathrm{D}}\left(\mathrm{I}-\mathrm{D} / 2+k \mathrm{D}^{2}+\right) \log n \\
& =\int \log n d n-\frac{1}{2} \log n+k / n+\ldots \\
& =n \log n-n-\frac{1}{2} \log n+\mathrm{C} .
\end{aligned}
$$

The constant can readily be evaluated by the use of Wallis's expression for $\pi$.

20 Woodside Terrace, Darlington,

JAMES Strachan.

February 23.

\section{Echinoderm Larvæ and their Bearing on Classification.}

THOUGH loth to prolong this discussion, I wish, in fairness to Dr. Mortensen and myself, to say that I did not accuse Dr. Mortensen of regarding the echinoderm metamorphosis as a case of metagenesis. What I did write in NATURE for December 8, I92I, seems to agree entirely with Dr. Mortensen's statement on March Io, I923-a statement accepted by Prof. MacBride.
Against Dr. Mortensen's view, that the sucking disc of Brachiolaria is a relatively recent acquisition, Prof. MacBride would cite $m e$ as in substantial agreement with himself (NATURE, January $\mathrm{r}_{3}$ ). That agreement extends to our common belief that all groups of echinoderms have passed through a fixed stage at some time in their ancestral history. On the precise relation of that fixed stage to the adult structure in the case of the starfish, we do not agree. Dr. Mortensen, it appears, is one of those who support my particular view. The sucking disc of the Brachiolaria has certainly been regarded by me, as by Prof. MacBride, as confirmatory evidence of the general theory. But if, as Dr. Mortensen now suggests, it be a secondary development, the theory does not necessarily fall, and Dr. Mortensen distinctly says that it does not. On the other hand, assuming Dr. Mortensen to be correct in his assertion that the forms with such a larva are only the more specialised, the sucker may none the less perpetuate an ancestral structure.

Until the geological history of the starfishes has been more fully worked out along the lines followed by Dr. W. K. Spencer, it is safer to express no opinion on the classification of the forms now living.

March II.

$$
\text { F. A. Bather. }
$$

\section{Constitution of Black Maketu Sand.}

We have made a careful chemical and X-ray analysis of the black sand from Maketu, N.Z., from which Dr. Alexander Scott believed he had isolated the oxide of a new element. We are able to confirm Prof. Bohr's conclusion that no new element is present.

Starting with Iooo grams of the sand we obtained I.7 grams of material free from silica, and insoluble in sulphuric acid. Fusion with sodium bisulphate did not bring this into solution, thus confirming Dr. Scott's experience, but it is interesting to note that on fusion with potassium bisulphate the residue went into solution completely, and was found by both chemical and X-ray analysis to consist of about equal parts of iron and aluminium. Prof. Bohr found an appreciable quantity of titanium in the residue, while we found no more than a trace; but as our residue was only 0.2 per cent of the ore our extraction was probably more complete.

\section{Research Laboratories, \\ General Electric Co., Ltd. Wembley, March 8.}

C. J. Smithells.

F. S. GOUCHER.

\section{Scientific Periodicals for Gzech Students.}

I HAVE recently received a most earnest and pathetic request from a group of $\mathrm{Czech}$ students at the University of Prague asking me whether this Society could send them an English scientific periodical. Unfortunately we have no funds for this, but it has struck me that it might be possible for some of your subscribers, who perhaps do not have their copies of NATURE bound, to let me have them to send to these students. It would be a really kind and charitable act, and would be helpful in promoting the good feeling between ourselves and the Czecho-Slovaks, which is so useful at the present time.

If the papers were to be sent from London, I could arrange to call for them at stated times, so that no trouble of packing or postage would be involved.

The Czech Society of Great Britain, B. O. TufNell.

Kensington Palace Mansions, W.8, March 2. 